\title{
THE IMPORTANCE OF DRAWING IN THE ARCHITECTURE PROJECT AND ITS TEACHING
}

\author{
Alba Dorado, María Isabel \\ Departamento de Arte y Arquitectura \\ Universidad de Málaga, SPAIN. Campus de Excelencia Internacional Andalucía Tech \\ maribelalba@uma.es
}

\begin{abstract}
We start designing working and thinking with our hands. With them, we can shape an external object first and think and develop the architectural project through it. When designing, our hands act as tools that move between the worlds of matter and thought, making it possible to work with our ideas, clarifying them and fixing them up into something buildable. From the drawing, the performing of sketches, models, collages ... we can travel that road made by ideas to enter a world of physical reality through a process in which the actions of thinking, drawing and building continually succeed each other.
\end{abstract}

This article tries to explore the role of our hands when designing in order to learn more about the process of creating the architectural project and the way it is generated, to finally speak about issues interesting for us concerning the way they are taught.

Every project comes into existence through a handmade object. Hands move through the paper whiteness, the pencil start fixing strokes on its surface, sometimes fast, sometimes slowly, and sometimes, with different intensities. Shapes yet to be defined, barely sketched, features of forms still emerging... constitute, at the beginning of the project, a series of acts which commence it and will develop in time.

During this process, drawing assumes a prominent role, not only as an instrument allowing the representation of the projectual idea itself, making it visible and defining its materialization and construction, but also as an element that generates thinking, as it is through drawing that we can work and think on the idea that originates it.

Drawing, writing, building models..., in short, working with your hands consciously, leads us to develop a thinking process in which gaze and hands work together. It would be necessary to claim that action for the teaching of architectural projects as a method of doing and thinking. During the project development, it would be necessary for students to learn how to work with instruments, tools... that resist the achievement of mere projections or mechanical representations of those things before their eyes, to get into the being of things, their presence or their being present.

In this respect, and in the field of the architectural project teaching, it is essential to highlight the importance of drawing due to its effectiveness to transmit and express a form of thinking.

As Martin Heidegger suggests, our hands are organs for our thinking. When they are not working in order to know or learn, they are thinking. Drawing, building models, sketching... is a matter of "doing" that turns into a way of "thinking" where hands and ideas are joined together as long as the project is carried out. Therefore, the value of drawing lies in its function as a tool for reflection.

Designing means to think in a graphic way, to materialise our ideas through our hands to work with them, think about them and, to materialize them once more. Sketches, models, collages, schemes... suitable for every step during the project development allow us to check the different design options, test and error trials. These act as critical instruments that inform about the validity of every decision taken. This is why the project cannot emerge from the mere application of a static, definitely established knowledge, but from a dialectical process between thought and action, gaze and hands.

Therefore, we could say that the drawing is an instrument of reflection that allows us to focus our thoughts, to define a support to contain, shape and define them, and to communicate the essence of our ideas, specifying and fixing them to turn them into something buildable. 
Hence the importance in the development of any project and in his teaching not only of those drawings that shape that graphic documentation enabling the building of architecture in every aspect, but also of the early drawings, sketches, schematic drafts, ideograms and series of images that try to study its context... and already contain the first projectual idea, clear and definitive, anticipating the formalisation of the project and sensing some material, building and structural conditions.

Keywords: Learning, teaching, creative, methodology, architecture, architectural project, hands, drawing. 